\title{
Tourism Demand Forecasting: A Time Varying Parameter Error Correction Model
}

\author{
GANG LI ${ }^{\mathrm{a}}$, KEVIN K. F. WONG ${ }^{\mathrm{b}}$, HAIYAN SONG ${ }^{\mathrm{b} 1}$, AND STEPHEN F. WITT ${ }^{\mathrm{b}}$ \\ ${ }^{a}$ School of Management, University of Surrey, Guildford GU2 7XH, United Kingdom \\ ${ }^{b}$ School of Hotel and Tourism Management, The Hong Kong Polytechnic University, \\ Hung Hom, Kowloon, Hong Kong
}

The advantages of error correction models (ECMs) and time varying parameter (TVP) models have been discussed in the tourism forecasting literature. These models are now combined to give a new single-equation model, the time varying parameter error correction model (TVP-ECM), which is applied for the first time in the context of tourism demand forecasting. The empirical study focuses on tourism demand, measured by tourism spending per capita, by UK residents for 5 key Western European destinations. Based on the discussion of how the series considered related to most, the empirical results show that the TVP-ECM can be expected to outperform a number of alternative econometric and time series models in forecasting the demand for tourism. By measuring performance in terms of the accuracy of the forecasts of growth (rates of change) and showing that TVP-ECM performs very well for this as well as conventional assessment of the level of demand in this study, it is suggested that forecasters of tourism demand levels and growth rates can feel comfortable using TVP-ECM given that it is expected to perform well.

Key words: time varying parameter, error correction model, tourism demand, ex post forecasting, Kalman filte

1 Corresponding author. Tel: +852 2766 6372; Fax: +852 2362 9362; Email: hmsong@polyu.edu.hk.

Gang Li is a Lecturer in Economics in the School of Management, University of Surrey, United Kingdom. Kevin K. F. Wong is Associate Professor in the School of Hotel and Tourism Management, The Hong Kong Polytechnic University, Hong Kong. Haiyan Song is a Chair Professor of Tourism in the School of Hotel and Tourism Management, The Hong Kong Polytechnic University, Hong Kong. Stephen Witt is a Visiting Professor in the School of Hotel and Tourism Management, The Hong Kong Polytechnic University, Hong Kong, and is an Emeritus Professor at the University of Surrey, United Kingdom. The research was funded by the Competitive Earmarked Research Grant (Project Account: G-T675) from The Hong Kong Polytechnic University for which the authors are very grateful. The first author thanks the School of Hotel and Tourism Management, The Hong Kong Polytechnic University, for providing financial support and research facilities during his visit to the school as a Visiting Assistant Professor. 
Accurate forecasting of tourism demand plays important roles in tourism planning of both public and business sectors due to the perishable nature of tourism products. As far as government agencies are concerned, accurate forecasts of tourism flows facilitate their policy projection in various areas, such as price regulation, environmental quality control, and provision of sufficient infrastructures. As for tourism businesses aiming to maximize their profits, accurate forecasts can "avoid the financial costs of excess capacity or the opportunity costs of unfilled demand" (Frechtling 2001, p6).

Tourism demand forecasting has been attracting increasing attention in the last two decades by both tourism researchers and tourism practitioners. A number of univariate/time-series and econometric forecasting techniques have been applied to the tourism context. With regard to time-series forecasting, ARIMA model has won the greatest popularity. It has shown sound performance in a number of tourism forecasting studies such as Chu (1998) and Lim and McAleer (2002). The naïve nochange model showed its superior forecasting accuracy earlier tourism forecasting studies such as Mattin and Witt (1989). Both of them are often used as benchmarks for forecasting accuracy comparisons amongst other time-series or/and econometric models. Exponential smoothing method was also used frequently for tourism forecasting in the 1980s, and they showed satisfactory performance in direction change and trend change forecasting (see, for example, Witt and Witt, 1989 and 1991, respectively). Another category of forecasting techniques - the econometric approach-have been developed well in tourism forecasting studies. Such modern econometric methods as the error correction model (ECM) and the time varying parameter (TVP) model have been applied to the tourism context over the last decade. A comprehensive review of the recent developments in tourism forecasting techniques can be found in Li, Song, and Witt (2005a).

The advantages of using the ECM in tourism demand forecasting lie in its ability to capture the short-run dynamic characteristics of tourism demand given the long-run cointegration (equilibrium) relationship. In order words, the ECM reflects a dynamic self-correcting process of tourism demand behavior towards its long-run steady sate (Song, Witt, and Li 2003). In addition, ECMs can avoid the occurrence of spurious regression and multicollinearity problems, which may otherwise affect the reliability and accuracy of the econometric analyses.

Several ECM estimation methods have been used in tourism demand studies, for example, the Engle-Granger (1987) two-stage approach (EG-ECM), the WickensBreusch (1988) one-stage approach (WB-ECM), and the Johansen (1988) maximum likelihood approach (JML-ECM). All of these approaches have their merits (see, Song and Witt 2000 for detailed explanation), and no clear-cut evidence shows that one approach is consistently superior to the others. The EG-ECM is straight forward to estimate and it has been used frequently in recent studies on tourism demand forecasting (see, for example, Gonzalez and Moral, 1995, Kulendran and Wilson, 2000, and Song, Romilly, and Liu, 2000). Recent applications of other ECMs to tourism demand analysis include Dritsakis (2004), Lim and McAleer (2001, 2002), Narayna (2004), Webber (2001).

Another advance in econometric forecasting refers to the TVP technique. The TVP model relaxes the constancy restriction on the parameters to be estimated in a 
traditional fixed-parameter econometric model to take account of the possibility of parameter changes over time. Applications of the TVP model to tourism demand forecasting have shown its superiority over fixed-parameter econometric models in terms of short-run forecasting accuracy (see, for instance, Song, Witt, and Jensen 2003; Witt, Song, and Louvieris 2003).

There are two broad categories of econometric models that have been applied in tourism demand modeling and forecasting studies: the (usual) single-equation models (such as autoregressive distributed lag models (ADLMs) and ECMs) and (the much less common) system-of-equations models (such as the linear almost ideal demand system, or LAIDS). Amongst the single-equation tourism demand studies, so far the TVP technique has been applied only to static or long-run cointegration models. In the tourism forecasting literature, no publication has been found on the combination of the TVP technique with the ECM. With regard to the system-of-equations models, there has been only one study, by Li, Song, and Witt (2005b), which has introduced the TVP-ECM into the LAIDS framework. This study has demonstrated the improved forecasting performance of the TVP-ECM in comparison with its static counterpart. There has been no study in the tourism context which applies the single-equation TVP-ECM to demand forecasting and examines its forecasting ability relative to fixed-parameter single-equation econometric models. This paper therefore aims to bridge this gap in the tourism literature. For the first time, this study will introduce the single-equation TVP-ECM into tourism forecasting practice and present empirical evidence of enhanced forecasting accuracy over various fixed-parameter econometric models. With regard to tourism demand forecasting assessment, most studies have focused on the prediction of demand levels, while the ability of models to forecast the growth of tourism demand has been ignored. In practice, the change of tourism demand is of particular concern in tourism businesses, as in such a competitive environment of the tourism industry, business strategies need to be adjusted frequently according to the dynamic changes of the demand of their products. In this study both the level of tourism demand and the growth of tourism demand are considered in the forecasting evaluation.

\section{THE MODELS}

\section{The TVP-Long-Run Model (TVP-LRM)}

TVP models are normally specified in a state space form (SSF), and estimated by the Kalman filter algorithm (Kalman 1960). State space modeling was developed in the control engineering science and was introduced into economic analysis in the 1980s. It assumes that the dynamic features of the system under study are determined by the unobserved variables associated with a series of observations (Durbin and Koopman 2001). The state space presentation allows unobserved variables to be included into, and estimated along with, the observable model. By inferring the relevant properties of the unobserved series from the knowledge of the observations, the evolution of the system can be more precisely described and predicted. A linear SSF can be written as:

$$
\begin{gathered}
y_{t}=Z_{t}^{\prime} \alpha_{t}+\varepsilon_{t}, \quad \varepsilon_{t} \sim N\left(0, H_{t}\right), t=1, \ldots, T \\
\alpha_{t+1}=T_{t} \alpha_{t}+\eta_{t}, \quad \alpha_{1} \sim N\left(a_{1}, P_{1}\right), \eta_{t} \sim N\left(0, Q_{t}\right),
\end{gathered}
$$


where $y_{t}$ is the dependent variable; $Z_{t}$ is a vector of independent variables; $\alpha_{t}$ is an unobserved vector called state vector; $\varepsilon_{t}$ refers to the temporary disturbance and $\eta_{t}$ the permanent disturbance, $\varepsilon_{t}$ and $\eta_{t}$ are Gaussian disturbances, which are serially independent and independent of each other at all time points; The matrices $T_{t}, H_{t}$ and $Q_{t}$ are initially assumed to be known. Equation (1) is called the observation equation, and Equation (2) called the state equation. In most of the economic applications, the evolution of $\alpha_{t}$ is assumed to follow a multivariate random walk. i.e., $\alpha_{t+1}=\alpha_{t}+\eta_{t}$. This assumption is also applied in the current study. The initial value of $\alpha_{t}$, i.e., $\alpha_{1}$, can be estimated by maximum likelihood from the first few observations of $y_{t}$ and $Z_{t}$, and $P_{1}$ is its variance (Durbin and Koopman 2001; Harvey 1989).

Since the observation equation (1) is based on the classical econometric model-the static or long-run cointegration model, the TVP specification of Equation (1) is known as the TVP-LRM. The TVP-LRM only focuses on the variations of coefficients over time. Whether there is any long-run stable relationship is not a consideration. In other words, there is no short-run disequilibrium adjustment mechanism to be incorporated into the model specification.

The TVP model was not applied to tourism demand studies until the late 1990s, and its applications are still limited. Amongst these studies, Song and Witt (2000), Song, Witt, and Jensen (2003) and Witt, Song, and Louvieris (2003) have examined the TVP model's performance in forecasting international tourism demand in comparison with other fixed-parameter econometric models and time-series models. The first two studies assess forecasting accuracy in terms of error magnitude using the measures mean absolute percentage error (MAPE) and root mean squared percentage error (RMSPE). In both studies, the TVP model outperforms all the competitors including the autoregressive distributed lag model (ADLM), the vector autoregressive (VAR) model, ECMs and the naive no-change model in the one-year-ahead forecasting comparison. With regard to the overall (from one- to four-years-ahead) performance, the TVP model is still ranked top (evaluated by the RMSPE) in Song and Witt (2000) and above average in Song, Witt, and Jensen (2003). Witt, Song, and Louvieris (2003) investigate the forecasting performance of the TVP model in terms of both error magnitude and directional change. The comparison results show that in both assessments the TVP model is ranked second best amongst 7 candidates in the oneyear-ahead forecasting competition. Li, Song, and Witt (2005b) develop the TVPLAIDS and TVP-EC-LAIDS and compare their forecasting performances with the static AIDS. The empirical findings show that both TVP-LAIDS and TVP-EC-LAIDS outperform their static counterparts in all comparisons of one- to four-years-ahead forecasts. Since all of these empirical studies showed that the TVP technique is superior to the alternative econometric models for short-run tourism demand forecasting, further applications and developments of this approach should be encouraged.

\section{The TVP-ECM}

Engle and Granger (1987) show that in a system of two variables, if a long-run equilibrium relationship exists, the short-term disequilibrium relationship between the 
two variables can be represented by an ECM. Such an ECM can accommodate an adjustment process that prevents economic variables from drifting too far away from their long-run equilibrium time path (see, for example, Thomas 1993, p.153). Such a technique is very useful in the situations where both long-run equilibrium and shortrun disequilibrium behavior are of interest. It should be noted that if there are more than two variables in the system, it is possible that there will be more than one cointegrating relationships, and correspondingly the ECM becomes a vector, i.e., VECM. This case is beyond the discussion of this paper due to its irrelevance to the following empirical study.

According to the Engle-Granger two-stage approach (EG-ECM), testing for the longrun equilibrium relationship between a set of economic variables and modeling their short-run dynamics via an ECM can be carried out in a two-step procedure. Most economic variables are non-stationary or integrated of order 1, denoted as I (1), which means they need to be differenced before they become stationary. The first step of the Engle-Granger approach is to test for the cointegration relationship amongst the $I(1)$ variables, $y_{t}$ and $Z_{t}$, based on the static long-run equilibrium regression:

$$
y_{t}=Z_{t}^{\prime} \alpha+e_{t}
$$

where $\alpha$ (without a subscript) is a fixed parameter vector. After confirming the acceptance of a cointegration relationship, the second step is to estimate an ECM

$$
\Delta y_{t}=\sum_{i=0}^{p} \beta_{i} \Delta Z_{t-i}+\sum_{j=1}^{p} \phi_{j} \Delta y_{t-j}+\lambda \hat{e}_{t-1}+u_{t}
$$

where $\hat{e}_{t-1}=y_{t-1}-Z_{t-1} \hat{\alpha}$ are the OLS residuals from the cointegration function (3), representing the error correction mechanism; $p$ is the lag length; $\beta_{i}, \phi_{j}$ and $\lambda$ are parameters to be estimated; the value of $\lambda$ implies that the system will adjust itself toward equilibrium by removing $\lambda$ of a unit from the error made in the previous period (Song and Witt 2000).

The EG-ECM has been employed widely for forecasting and policy evaluation. Applications of the EG-ECM started to appear in the tourism literature a decade ago. For example, Kulendran and Wilson (2000) show that the EG-ECM performs better than the other two competitors: the naive no-change model and seasonal ARIMA models, in the one-quarter-ahead forecasting comparison. Song, Romilly, and Liu (2000) illustrate that the EG-ECM generally outperforms all the other models in their comparison including the VAR, AR(1), ARMA and naive models as far as one-yearahead forecasting is concerned. However, the EG-ECM does not perform well in the study by Gonzalez and Moral (1995) using monthly data. Its poor performance may be associated with the different data frequency in use. Therefore, as far as forecasts of seasonal tourism demand are concerned, the EG-ECM should be used with caution, and alternative forecasting models including other forms of ECMs should be considered.

The specification of the conventional fixed-parameter ECM, Equation (4), implies that the speed of short-run adjustment is constant over time. In the consistently changing economic environment such an assumption seems to be too strict and 
arbitrary. In fact, "even assuming the existence of a stable long-run combination, one may find signs of instability in the short-run adjustment mechanism" (Ramajo 2001). Therefore, it is more easily understandable to specify the TVP short-run dynamics within the long-run equilibrium framework, i.e., the TVP-ECM.

As with the TVP-LRM, the TVP-ECM can be specified in an SSF. In the case where the lag length of the different variables is zero, which has been proved to be appropriate in most tourism studies using annual datasets, the observation equation of the TVP-ECM can be written as:

$$
\Delta y_{t}=\Delta Z_{t}^{\prime} \beta_{t}+\lambda_{t} \hat{e}_{t-1}+v_{t}
$$

where $\beta_{t}$ is the time-varying parameter vector, and $v_{t}$ is the temporary disturbance term. The state equation still takes the same form as Equation (2), and $\alpha_{t}=\left(\beta_{t}, \lambda_{t}\right)^{\prime}$.

It should be noted that dummy variables can be readily incorporated into both the TVP-LRM and the TVP-ECM in order to capture the effects of one-off events such as the Gulf War and the Oil Crises. Since these one-off events are regarded as exogenous factors for tourism demand, it is not necessary to estimate the parameters using the TVP technique and fixed parameters are appropriate for dummy variables in a TVP model.

So far there has been no application of the TVP-ECM to single-equation modeling and forecasting of tourism demand, and its forecasting performance, relative to other fixed-parameter single-equation approaches, has not been examined. This paper bridges this gap by applying the TVP-ECM to modeling and forecasting UK tourism demand in some key Western European destinations and comparing its forecasting performance with other single-equation econometric models.

\section{EMPIRICAL RESULTS AND DISCUSSION}

Western Europe is the most popular destination area for UK residents. Within this area, France, Spain, Italy, Greece and Portugal are the major destinations. Demand for tourism in these five destinations accounts for about $70 \%$ of the total in this region. Therefore, a great deal of attention is paid to these nations by those tourism businesses operating in this region. This study will therefore focus on these five destinations in Western Europe. It should be noted that demand for tourism in these five destinations has different characteristics. Spain, Italy, Greece and Portugal feature leisure destinations, while France receives a larger proposition of business travelers as well as holiday makers. With regard to the magnitude of tourism demand, measured by tourism spending in these destinations, it spreads into three levels: France and Spain each receive more than $20 \%$ of the total spending by UK visitors in Western Europe, Italy and Greece accounts for $8 \%$ or so, while only $4 \%$ goes to Portugal. As with most tourist destinations, demand in these five countries all experience growth to some extent in the long run (see Figure 1). However, it presents different growth patterns and speeds in these counties. For example, demand for France, Italy and Portugal shows gradual and stable evolvements, while that for Spain and Greece experiences more fluctuations. Since the destinations included in this study present a reasonably wide coverage of different scenarios, the empirical results 
of this study are likely to be applied to analysis of tourism demand for other countries or regions.

FIGURE 1

TOURISM SPENDING BY UK RESIDENTS IN SELECTED DESTINATIONS

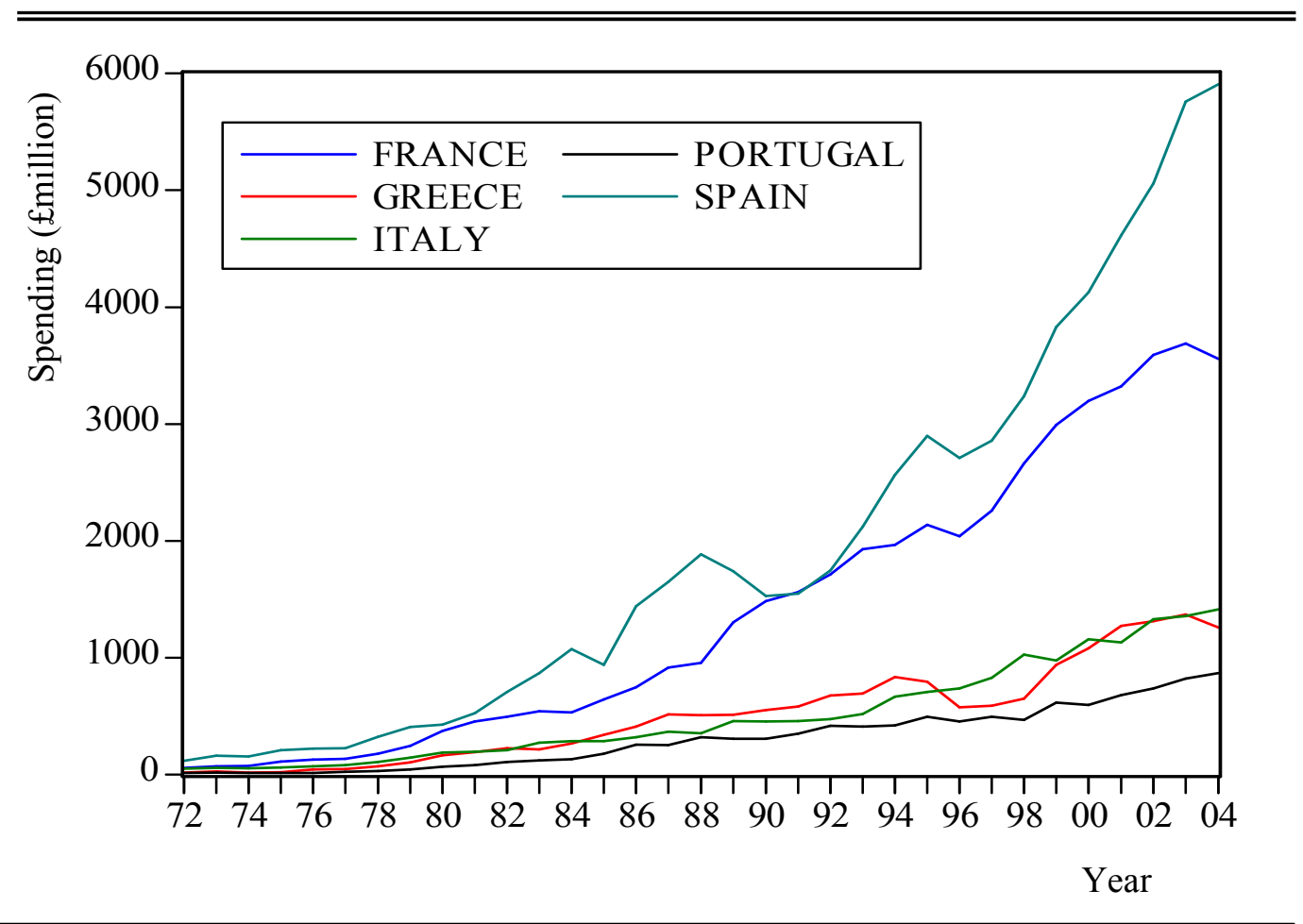

\section{Data and Variables}

The tourism demand function is written in the following form for each of the five destinations:

$$
L_{S P P I}=f\left(L H D I P I, L R C P I_{i}, L_{R S P I}, D U M 74, D U M 91\right)
$$

where $L$ in each variable indicates logarithm; $S P P I_{i}$ is tourism demand for destination $i(i=1,2, \ldots, 5)$, measured by the real tourism spending per capita in the destination covering all travel purposes and means. It is calculated by dividing the nominal tourism spending by the UK population, adjusted by the consumer price index (CPI) in destination $i$ and the appropriate exchange rate; HDIPI is the income of UK tourists, measured by the index of household disposable income per capita in constant prices $(1995=100) ; R C P I_{i}$ and $R S P I_{i}$ are the relative price and substitute prices, respectively. The relative price is calculated based on Song and Witt (2000), i.e., it is calculated by dividing the CPI in destination $i$ by that of the UK, adjusted by the appropriate exchange rate. The substitute price for each of the five equations is calculated as the weighted average of relative prices of the other four destinations, with shares of spending in these potential substitute destinations being weights. In addition, two dummy variables (DUM74 and DUM91) are incorporated to account for the effects of the Oil Crises in 1974-1975 and the Gulf War in 1991. 
Since the demand is measured by tourism spending within the destination, travel cost between the origin and destination countries is not included as an explanatory variable. Besides the above economic variables, other factors, such as destination imagery, competing travel modes and tourists' demographic features, may also influence the demand for tourism. However, due to the unavailability of the time series of these variables, they are excluded from the econometric analysis at a macro level. Since the purposes of this study are to illustrate the evolvement of demand elasticities over a long time period using the TVP technique and to examine the TVP models' forecasting performance in the short to medium term (1-4 years ahead), annual data over the last 33 years (1972-2004) are used in this study. Based on annual data and the specifications of the adopted TVP models which do not accommodate seasonal effects, this study therefore is not to analyze seasonality of tourism demand, while it is of interest of future studies. Tourism spending data (in nominal terms) are collected from the International Passenger Survey (IPS), published in Travel Trends (various issues), and income data are collected from Economic Trends (2001), both published by the Office for National Statistics (ONS), UK. The data on prices, exchange rates and population are collected from International Financial Statistical Yearbook (various issues) published by the International Monetary Fund.

Before model estimation, unit root tests need running to examine the stationary property of all the variables. Both Augmented Dickey-Fuller test and Phillips-Perron test suggest that all the above variables excluding dummies are $I$ (1) series. The hypothesis test for the optimal lag suture of the dynamic model (ADLM) for each destination suggest lag length equal to one is appropriate for each variable. Correspondingly, no lag terms of the differenced variables are required to be included in the ECMs. The further Johansen cointegration test shows that one cointegration relationship exists in each model. ${ }^{2}$ Therefore, ECM representations are to be used in the following model estimations.

\section{Kalman Filter Estimates of the TVP-LRM and TVP-ECM}

The above tourism demand function (5) can be rewritten in the SSF and following the Engle-Granger two-stage approach, both the TVP-LRM and TVP-ECM can be estimated using the Kalman filter algorithm. The computing program of EViews 5.0 is adopted for the model estimation. The estimates of the TVP-LRM and the TVP-ECM for each destination are shown in Tables 1 and 2, respectively. The parameters reported are the estimates at the end of the sample period. In such a log-log model, the coefficients of income, own-price and substitute prices variables show the level of various demand elasticities respectively. Parallel to fixed-parameter econometric models, a well-specified TVP model should also pass various diagnostic tests. Three diagnostic tests: non-normality, heteroscedasticity and predictive failure, are carried out in each estimated equation (technical illustrations of these tests are available in Harvey 1989, Chapter 5). Apart from the Greece TVP-LRM which suffers from heteroscedasticity, the other equations pass all the diagnostic tests. These results suggest that the TVP specification is appropriate for the tourism demand data studied.

\footnotetext{
${ }^{2}$ The results of unit root tests and cointegration tests are not presented because of space constraints but are available from the authors upon request.
} 
TABLE 1

ESTIMATES OF FINAL TVP-LRMs (Dependent Variable: LSPPI)

\begin{tabular}{|c|c|c|c|c|c|}
\hline & France & Greece & Italy & Portugal & Spain \\
\hline Constant & -0.031 & -0.139 & -0.058 & -0.055 & -0.093 \\
\hline LHDIPI & $\begin{array}{r}2.817 * * \\
(0.125)\end{array}$ & $\begin{array}{c}1.834^{*} \\
(0.821)\end{array}$ & $\begin{array}{r}1.935 * * \\
(0.267)\end{array}$ & $\begin{array}{c}1.779 * * \\
(0.678)\end{array}$ & $\begin{array}{r}2.220 * * \\
(0.547)\end{array}$ \\
\hline LRCPI & $\begin{array}{r}-1.163 * * \\
(0.286)\end{array}$ & $\begin{array}{r}-1.959^{* *} \\
(0.345)\end{array}$ & $\begin{array}{r}-1.184^{* *} \\
(0.217)\end{array}$ & $\begin{array}{r}-0.161 \\
(0.540)\end{array}$ & $\begin{array}{r}-1.230 * \\
(0.489)\end{array}$ \\
\hline LRSPI & $\begin{array}{c}0.997 * \\
(0.471)\end{array}$ & $\begin{array}{r}0.506 \\
(0.849)\end{array}$ & $\begin{array}{r}-0.502^{* *} \\
(0.121)\end{array}$ & $\begin{array}{c}-0.725 * \\
(0.348)\end{array}$ & $\begin{array}{r}-0.478 \\
(0.853)\end{array}$ \\
\hline DUM74 & -0.081 & -0.498 & & -0.177 & \\
\hline DUM91 & & & & & -0.176 \\
\hline Log likelihood & 19.118 & 2.202 & 16.920 & 9.620 & 8.800 \\
\hline $\mathrm{NO}(2)$ & 0.041 & 1.448 & 1.182 & 1.980 & 1.654 \\
\hline $\mathrm{HE}(9,9)$ & 3.039 & 3.031 & 1.374 & 1.441 & 0.664 \\
\hline $\operatorname{PF}(8,20)$ & 1.461 & 1.296 & 1.245 & 1.131 & 0.404 \\
\hline
\end{tabular}

Note: values in parentheses are the root mean standard errors. Whether to include the dummy variables in the above TVP-LRMs is decided by their statistical significance in the fixed-parameter cointegration models. NO refers to non-normality test, HE heteroscedasticity test, PF the Chow predictive failure test. For the statistical tests, the numbers in parentheses are the degrees of freedom. *significant at the $5 \%$ level, and ** significant at the $1 \%$ level.

TABLE 2

ESTIMATES OF FINAL TVP-ECMs (Dependent Variable: $\triangle$ LSPPI)

\begin{tabular}{|c|c|c|c|c|c|}
\hline & France & Greece & Italy & Portugal & Spain \\
\hline$\Delta$ LHDIPI & $\begin{array}{c}1.321 * * \\
(0.400)\end{array}$ & $\begin{array}{r}0.532 \\
(1.633)\end{array}$ & $\begin{array}{r}1.531 * * \\
(0.489)\end{array}$ & $\begin{array}{r}1.750 \\
(2.910)\end{array}$ & $\begin{array}{r}2.418 * * \\
(0.602)\end{array}$ \\
\hline$\Delta \mathrm{LRCPI}$ & $\begin{array}{r}-0.591 \\
(0.320)\end{array}$ & $\begin{array}{r}-.1407 * * \\
(2.900)\end{array}$ & $\begin{array}{c}-0.947 * * \\
(0.2592)\end{array}$ & $\begin{array}{r}-1.170^{* *} \\
(0.336)\end{array}$ & $\begin{array}{r}-0.238 \\
(0.369)\end{array}$ \\
\hline$\Delta \mathrm{LRSPI}$ & $\begin{array}{r}-0.368 \\
(0.233)\end{array}$ & $\begin{array}{r}0.214 \\
(0.216)\end{array}$ & $\begin{array}{r}-0.231 \\
(0.186)\end{array}$ & $\begin{array}{r}0.728 \\
(0.997)\end{array}$ & $\begin{array}{r}-0.226 \\
(0.286)\end{array}$ \\
\hline $\mathrm{EC}(-1)$ & $\begin{array}{r}-0.529 * * \\
(0.129)\end{array}$ & $\begin{array}{r}-0.429 * * \\
(0.108)\end{array}$ & $\begin{array}{r}-0.783 * * \\
(0.174)\end{array}$ & $\begin{array}{c}-0.565 * * \\
(0.0927)\end{array}$ & $\begin{array}{r}-0.602 * * \\
(0.143)\end{array}$ \\
\hline$\triangle \mathrm{DUM} 74$ & -0.089 & -0.485 & & -0.113 & \\
\hline$\triangle$ DUM91 & & & & & -0.120 \\
\hline Log likelihood & 25.147 & 10.262 & 18.756 & 8.506 & 12.939 \\
\hline $\mathrm{NO}(2)$ & 1.274 & 0.633 & 1.207 & 1.483 & 1.166 \\
\hline $\operatorname{HE}(8,8)$ & 1.096 & 1.100 & 1.591 & 0.554 & 0.161 \\
\hline $\operatorname{PF}(8,18)$ & 1.153 & 0.648 & 1.329 & 0.823 & 0.226 \\
\hline
\end{tabular}

Note: see Table 1. 
FIGURE 2

KALMAN FILTER ESTIMATES OF COEFFICIENTS IN THE FRANCE TVP-ECM

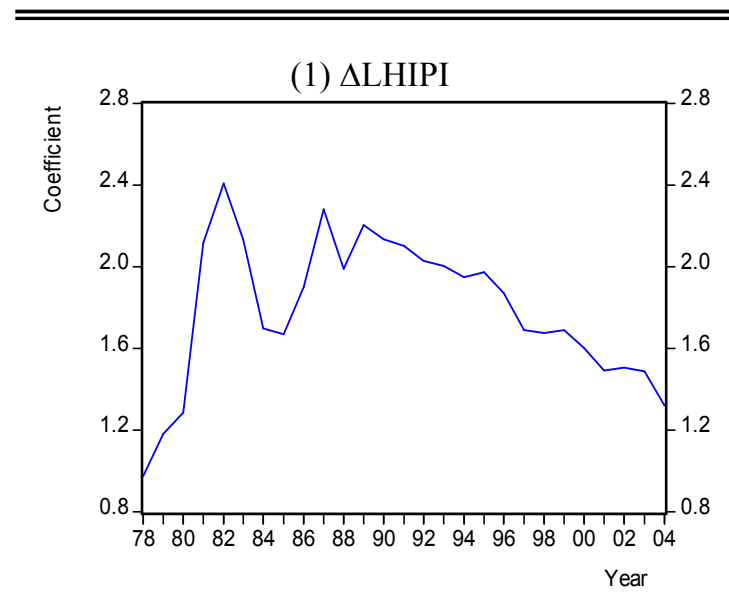

(2) $\triangle$ LRCPI

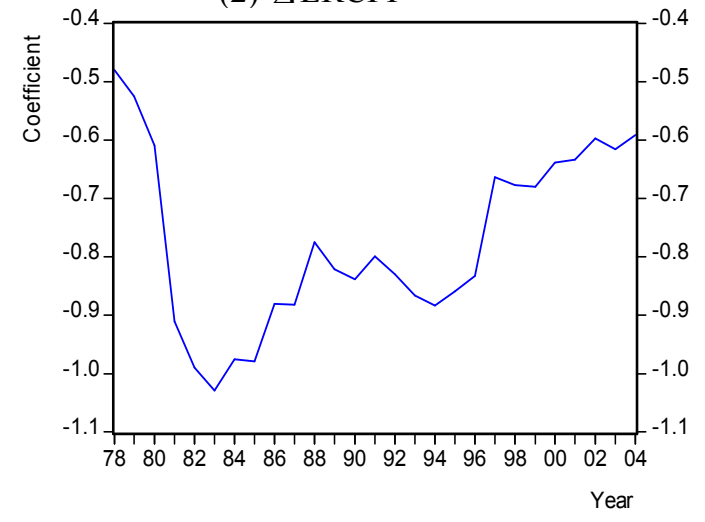

(3) $\triangle$ LRSPI

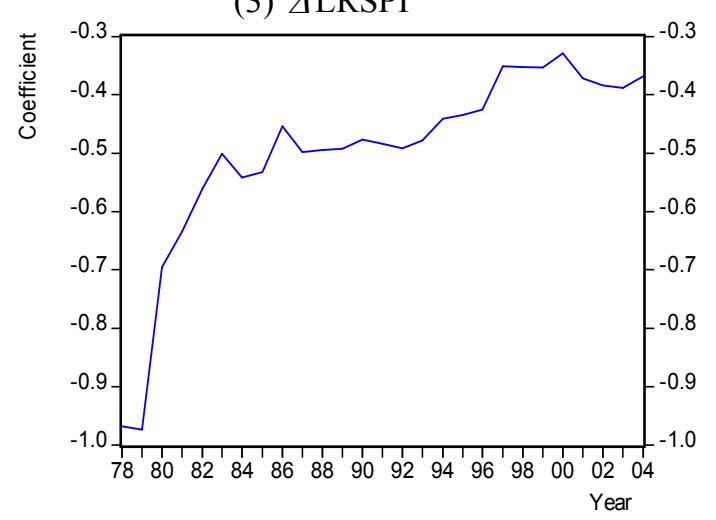

(4) EC

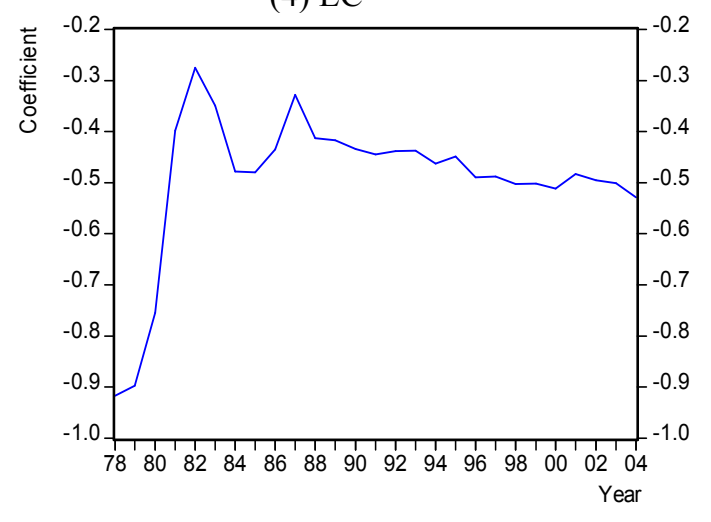

Note: since the diffuse initialization in the Kalman filter algorithm consumes a few observations at the beginning of the data set, the valid plots start from 1978.

Figure 2 presents the Kalman filter estimates of the coefficients in the France TVPECM. The figures related to other destinations are also available from the authors upon request. The first three diagrams indicate the evolutions of the short-run income, own-price and cross-price elasticities over time. For example, diagram (1) suggests adecreasing short-run income elasticity, especially since the mid 1980s. The implication is that with increasing disposable income, UK residents regard travel to France as less and less of a luxury. With regard to the short-run own-price elasticity, diagram (2) indicates that UK residents' demand for tourism in France has become less and less sensitive to price changes in general over the last twenty years, and this can be seen from the decreasing (absolute) values of the own-price coefficients. This finding reflects the phenomenon that mass tourism is losing its popularity in Western Europe and price reduction may no longer be a highly effective marketing strategy. On the contrary, product differentiation and value added are more likely to be effective in the current state of competition in the tourism industry. The rising values 
(from negative to positive) of the coefficient of substitute price suggest that both substitution and complementary effects exist amongst the relationships between France and the other four top UK destinations under investigation, and substitutability has become more and more dominant especially during the last few years of the study. This can be explained by the severe competition between France and Spain, the two most popular destinations for UK tourists. This relationship was also apparent in previous studies such as De Mello, Pack, and Sinclair (2002) and Li, Song, and Witt (2004). Diagram (4) refers to the evolution of the coefficient of the error term. The fluctuations confirm the earlier argument that it is more appropriate to assume changing speeds of the short-run adjustment in the system.

\section{Estimation of Fixed-Parameter Econometric Models}

In order to assess the forecasting performance of the TVP-LRM and TVP-ECM relative to fixed-parameter econometric models, the following models are included in the comparison: the ADLM in a reduced form where only statistically significant variables are kept in the final model; VAR model; Wickens and Breusch ECM (WBECM); Johansen maximum likelihood ECM (JML-ECM); and Engle Granger ECM (EG-ECM), all in the fixed-parameter framework. Due to space constraints, only the estimates of the France case are reported (see Table 3), while the others are also available from the authors upon request.

\section{Ex post Forecasting Comparison}

The forecasting performances of the TVP-LRM and the TVP-ECM are compared with those of the fixed-parameter econometric models discussed above. Two univariate time series models (ARIMA and naive no-change models) along with the static econometric model are also included in the evaluation as benchmarks. All of the above models used for the forecasting comparison are re-estimated, first using data for the sample period 1972-1996, and the rest of data are used for ex post forecasting accuracy comparison. Then the sample period is extended to one year later each time until 2003 for model re-estimation and forecast projection. This study focuses on oneto four-years-ahead forecasting comparison, with the longer forecasting horizons being ignored due to fewer forecasts being available and lack of robustness in comparison evaluation. The performance of the models in forecasting both demand levels and growth (in relation to the levels and differenced dependent variables, respectively) is evaluated. Forecasting errors are measured by both MAPE and RMSPE. Due to high consistency between the two measures in this study, only the results of MAPE are reported (see Table 4). 
TABLE 3

ESTIMATES OF FIXED-PARAMETER ECONOMETRIC MODELS FOR FRANCE

\begin{tabular}{|c|c|c|c|c|c|c|c|}
\hline & \multicolumn{3}{|c|}{ Dependent Variable: LSPPI } & & \multicolumn{3}{|c|}{ Dependent Variable: $\Delta$ LSPPI } \\
\hline & Static & ADLM & VAR & & WB-ECM & JML-ECM & EG-ECM \\
\hline$\overline{\text { Constant }}$ & $\begin{array}{l}-0.100^{*} \\
(0.043)\end{array}$ & $\begin{array}{l}-0.064 \\
(0.034)\end{array}$ & $\begin{array}{c}0.043 \\
(0.055)\end{array}$ & Constant & $\begin{array}{c}-0.069 \\
(0.040)\end{array}$ & $\begin{array}{c}0.018 \\
(0.030)\end{array}$ & \\
\hline LSPPI(-1) & & $\begin{array}{c}0.425^{* *} \\
(0.107)\end{array}$ & $\begin{array}{l}0.456^{*} \\
(0.238)\end{array}$ & $\triangle \mathrm{LRCPI}$ & $\begin{array}{l}-0.890^{*} \\
(0.400)\end{array}$ & & $\begin{array}{l}-0.750^{*} \\
(0.314)\end{array}$ \\
\hline LRCPI & $\begin{array}{c}-2.258^{* *} \\
(0.340)\end{array}$ & $\begin{array}{c}-1.150^{* * *} \\
(0.169)\end{array}$ & & $\Delta$ LRSPI & $\begin{array}{c}-0.378 \\
(0.381)\end{array}$ & & $\begin{array}{l}-0.372 \\
(0.303)\end{array}$ \\
\hline LRCPI(-1) & & $\begin{array}{l}-0.656^{*} \\
(0.311)\end{array}$ & $\begin{array}{l}-1.059^{*} \\
(0.626)\end{array}$ & $\Delta$ LHDIPI & $\begin{array}{l}1.596^{*} \\
(0.696)\end{array}$ & & $\begin{array}{l}2.130 * * \\
(0.437)\end{array}$ \\
\hline LRSPI & $\begin{array}{l}0.850^{*} \\
(0.319)\end{array}$ & & & LSPPI(-1) & $\begin{array}{l}-0.381^{*} \\
(0.148)\end{array}$ & & \\
\hline LRSPI(-1) & & $\begin{array}{c}0.838^{* *} \\
(0.219)\end{array}$ & $\begin{array}{c}0.361 \\
(0.432)\end{array}$ & LRCPI(-1) & $\begin{array}{l}-1.251^{*} \\
(0.510)\end{array}$ & & \\
\hline LHDIPI & $\begin{array}{c}2.200^{* *} \\
(0.133)\end{array}$ & $\begin{array}{l}1.042 * * \\
(0.256)\end{array}$ & & LRSPI(-1) & $\begin{array}{c}0.508 \\
(0.333)\end{array}$ & & \\
\hline LHDIPI(-1) & & & & LHDIPI(-1) & $\begin{array}{c}0.662 \\
(0.400)\end{array}$ & & \\
\hline \multirow[t]{2}{*}{ DUM74 } & $\begin{array}{c}-0.232 * * \\
(0.088)\end{array}$ & $\begin{array}{c}-0.151^{* *} \\
(0.058)\end{array}$ & $\begin{array}{l}-0.181^{*} \\
(0.107)\end{array}$ & $\Delta$ DUM74 & $\begin{array}{l}-0.030 \\
(0.070)\end{array}$ & $\begin{array}{l}-0.131 \\
(0.901)\end{array}$ & $\begin{array}{l}-0.076 \\
(0.071)\end{array}$ \\
\hline & & & & $\operatorname{ECM}(-1)$ & & $\begin{array}{l}-0.282^{*} \\
(0.115)\end{array}$ & $\begin{array}{c}-0.484 * * \\
(0.160)\end{array}$ \\
\hline $\bar{R}^{2}$ & 0.979 & 0.991 & 0.976 & $\bar{R}^{2}$ & 0.600 & 0.123 & 0.598 \\
\hline $\mathrm{SC}(1)$ & 2.046 & 0.933 & 3.550 & $\mathrm{SC}(1)$ & 0.730 & 3.150 & 1.779 \\
\hline $\mathrm{FF}(1)$ & $19.712 * *$ & $9.859^{* *}$ & $6.299^{*}$ & $\mathrm{FF}(1)$ & 1.479 & 0.199 & 0.121 \\
\hline $\mathrm{NO}(2)$ & 2.185 & 1.340 & 3.261 & $\mathrm{NO}(2)$ & 1.061 & 0.045 & 0.801 \\
\hline $\mathrm{HE}(1)$ & 4.528 & 5.520 & 0.865 & $\mathrm{HE}(1)$ & 14.564 & 2.929 & 4.025 \\
\hline $\operatorname{PF}(\mathrm{df})$ & $3.031 *$ & 0.787 & 0.525 & $\mathrm{PF}(\mathrm{df})$ & 1.573 & 0.464 & 1.180 \\
\hline
\end{tabular}

Note: Values in parentheses are standard errors. SC(1) is the Lagrange multiplier test for serial correlation, $\mathrm{NO}(2)$ is the Jarque-Bera normality test, $\mathrm{FF}(1)$ is the Ramsey's misspecification test, $\mathrm{HE}(1)$ is a heteroscedasticity test, $\mathrm{PF}(\mathrm{df})$ is the Chow predictive failure test, and $\mathrm{df}$ is the degrees of freedom. All apart from the Chow statistic are Chi-square statistics. The Chow test is an F statistic. Fore the statistical tests, the numbers in parentheses are the degrees of freedom.

** and * indicate the $1 \%$ and $5 \%$ significance levels. 
TABLE 4

FORECASTING ACCURACY OVER DIFFERENT FORECASTING HORIZONS

\begin{tabular}{|c|c|c|c|c|c|c|c|c|c|c|c|}
\hline Horizon & Measure & Naive & ARIMA & Static & ADLM & VAR & WB-ECM & JML-ECM & EG-ECM & TVP-LRM & TVP-ECM \\
\hline 1-year-ahead & MAPE & $0.446(8)$ & $0.498(9)$ & $0.961(10)$ & $0.334(4)$ & $0.368(6)$ & $0.411(7)$ & $0.355(5)$ & $0.309(3)$ & $0.206(1)$ & $0.214(2)$ \\
\hline 2-years-ahead & MAPE & $0.602(9)$ & $0.592(8)$ & $0.929(10)$ & $0.388(4)$ & $0.432(5)$ & $0.565(7)$ & $0.265(3)$ & $0.460(6)$ & $0.174(1)$ & $0.222(2)$ \\
\hline 3-years-ahead & MAPE & $0.639(10)$ & $0.483(8)$ & $0.568(9)$ & $0.245(3)$ & $0.475(7)$ & $0.332(5)$ & $0.347(6)$ & $0.328(4)$ & $0.208(2)$ & $0.163(1)$ \\
\hline 4-years-ahead & MAPE & $0.702(10)$ & $0.476(7)$ & $0.610(9)$ & $0.282(3)$ & $0.524(8)$ & $0.420(6)$ & $0.374(4)$ & $0.391(5)$ & $0.218(2)$ & 0.164 (1) \\
\hline Overall & MAPE & $0.597(9)$ & $0.512(8)$ & $0.767(10)$ & $0.312(3)$ & $0.450(7)$ & $0.432(6)$ & $0.335(4)$ & $0.372(5)$ & $0.202(2)$ & $0.191(1)$ \\
\hline 1-year-ahead & MAE & $0.132(8)$ & $0.135(9)$ & $0.220(10)$ & $0.097(4)$ & $0.107(5=)$ & $0.111(7)$ & $0.107(5=)$ & $0.095(3)$ & $0.054(1)$ & $0.070(2)$ \\
\hline 2-years-ahead & MAE & $0.119(8)$ & $0.121(9)$ & $0.126(10)$ & $0.092(3)$ & $0.102(6)$ & $0.100(4)$ & $0.101(5)$ & $0.089(2)$ & $0.116(7)$ & $0.074(1)$ \\
\hline 3-years-ahead & MAE & $0.115(7)$ & $0.117(8)$ & $0.130(10)$ & $0.093(3)$ & $0.124(9)$ & $0.098(4)$ & $0.111(6)$ & $0.086(2)$ & $0.105(5)$ & $0.070(1)$ \\
\hline 4-years-ahead & MAE & $0.098(4)$ & $0.112(8)$ & $0.142(10)$ & $0.088(2)$ & $0.113(9)$ & $0.105(7)$ & $0.100(5=)$ & $0.100(5=)$ & $0.094(3)$ & 0.087 (1) \\
\hline Overall & MAE & $0.116(8)$ & $0.121(9)$ & $0.155(10)$ & $0.093(4)$ & $0.111(7)$ & $0.104(5)$ & $0.105(5)$ & $0.092(2=)$ & $0.092(2=)$ & $0.075(1)$ \\
\hline
\end{tabular}

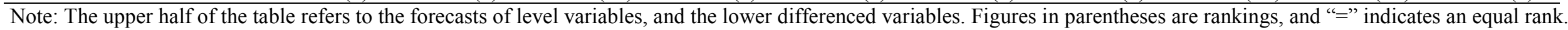


With regard to demand level forecasts, the TVP-ECM and TVP-LRM outperform the other models consistently over different forecasting horizons. Overall, they forecast at least $35 \%$ more accurately than the other models in the comparison. In particular, the TVP-LRM predicts most accurately among all the candidate models in one-year- and two-years-ahead forecasting. The superiority of the TVP-LRM in short-term forecasting detected in this study is in line with the findings in previous studies such as Song and Witt (2000). As far as longer forecasting horizons are concerned, the TVP-ECM performs even better than the TVP-LRM. It has been observed that the reduced ADLM outperforms all the other fixed-parameter ECMs in the overall evaluation of demand level forecasting and in all but two cases for different forecasting horizons. These results are consistent with other economic forecasting exercises. As Clements and Hendry (1998)'s findings suggest, when level variables are forecast, the levels specification without CI relationship being imposed outperform the ECMs. The naïve no-change model and the static econometric model, both of which take no account of dynamics of tourism demand, and the ARIMA model which does not consider the explanatory power of various economic factors in tourism demand modeling, always performed poorly and are ranked the bottom three amongst the ten competing models.

Insofar as tourism demand growth is concerned, the TVP-ECM and TVP-LRM appear to be top two again (and the EC-ECM performs equally well as the TVP-LRM) in terms of the overall performance. The TVP-LRM forecasts much more accurately than the other in the one-year-ahead occasion, but it does not show the superior performance in two- and three-years-ahead forecasting. The TVP-ECM shows greater consistency in terms of its outstanding performance in demand growth forecasting. The reduced ADLM and EG-ECM both predict consistently well over different forecasting horizons. As with demand level forecasting, the static and ARIMA models project the least accurate forecasts overall. Although the naïve model shows aboveaverage performance in the four-years-ahead forecasting, its performance in other occasions is much poorer. As a result, its overall rank for demand growth forecasting is only higher than the static and ARIMA model.

With regard to the overall performance of various models across different destinations under the study, Table 5 shows that either TVP-ECM or TVP-LRM appears to best model for the five destinations concerned, and they always appear to be top three amongst all the competitors. As for demand growth forecasting, the TVP-ECM gives the best or the second best performance in all cases except Portugal, where the TVPLRM appears to be the most accurate model. These results suggest that despite the different characteristics of the demand for tourism in the five destinations, the TVPECM and/or TVP-LRM always present superior performance for forecasting both demand level and growth. On the contrary, other models show divergent performance when different destinations are concerned. For example, although Table 4 shows the overall performance of the ADLM is satisfactory, it varies across different destinations. It forecasts the demand for tourism in France and Italy relatively accurately, while poor performance appears in Spain's case in both demand level and growth forecasting and in Portugal's case as far as demand growth is concerned. Great fluctuations of forecasting performance between different destinations can also be seen in the JML-ECM and EG-ECM, although they show sound overall performance in demand level and growth forecasting, respectively, when the results for the individual destinations are aggregated. 
TABLE 5

OVERALL FORECASTING ACCURACY ACCROSS DIFFERENT DESTINATIONS

\begin{tabular}{|c|c|c|c|c|c|c|c|c|c|c|c|}
\hline Destination & Measure & Naive & ARIMA & Static & ADLM & VAR & WB-ECM & JML-ECM & EG-ECM & TVP-LRM & TVP-ECM \\
\hline France & MAPE & $0.410(10)$ & $0.339(8)$ & $0.322(7)$ & $0.146(3)$ & $0.355(9)$ & $0.261(5)$ & $0.291(6)$ & $0.155(4)$ & $0.119(2)$ & $0.116(1)$ \\
\hline Greece & MAPE & $0.939(8)$ & $0.984(9)$ & $1.078(10)$ & $0.477(5)$ & $0.683(7)$ & $0.542(6)$ & $0.447(4)$ & $0.393(3)$ & $0.366(2)$ & $0.235(1)$ \\
\hline Italy & MAPE & $0.467(10)$ & $0.380(8)$ & $0.191(4=)$ & $0.175(2)$ & $0.345(7)$ & $0.191(4=)$ & $0.399(9)$ & $0.227(6)$ & $0.154(1)$ & $0.190(3)$ \\
\hline Portugal & MAPE & $0.623(7)$ & $0.522(5)$ & $1.989(10)$ & $0.439(4)$ & $0.561(6)$ & $1.250(9)$ & $0.293(2)$ & $0.964(8)$ & $0.220(1)$ & $0.297(3)$ \\
\hline Spain & MAPE & $0.546(10)$ & $0.337(8)$ & $0.253(5)$ & $0.325(7)$ & $0.304(6)$ & $0.498(9)$ & $0.246(4)$ & $0.122(2)$ & $0.149(3)$ & $0.116(1)$ \\
\hline France & MAE & $0.094(6=)$ & $0.113(9)$ & $0.130(10)$ & $0.077(3)$ & $0.099(8)$ & $0.094(6=)$ & $0.089(4)$ & $0.073(2)$ & $0.092(5)$ & $0.058(1)$ \\
\hline Greece & MAE & $0.169(8)$ & $0.184(9)$ & $0.193(10)$ & $0.094(2)$ & $0.161(7)$ & $0.115(4=)$ & $0.135(6)$ & $0.096(3)$ & $0.115(4=)$ & 0.084 (1) \\
\hline Italy & MAE & $0.134(8)$ & $0.140(10)$ & $0.109(5)$ & 0.098 (3) & $0.132(7)$ & $0.112(6)$ & $0.138(9)$ & $0.090(2)$ & $0.104(4)$ & 0.085 (1) \\
\hline Portugal & MAE & 0.089 (3) & $0.092(5=)$ & $0.238(10)$ & $0.114(7)$ & $0.085(2)$ & $0.159(9)$ & $0.092(5)$ & $0.146(8)$ & $0.083(1)$ & $0.091(4)$ \\
\hline Spain & MAE & $0.095(8)$ & $0.078(5)$ & $0.103(9)$ & $0.080(6=)$ & $0.080(6=)$ & $0.123(10)$ & $0.070(3)$ & $0.056(1)$ & $0.070(3=)$ & $0.058(2)$ \\
\hline
\end{tabular}

Note: See Table 4. 
The above results in this study suggest that the TVP technique, especially in the specification of TVP-ECM, contributes to consistent improvements of accuracy of tourism demand forecasting, regardless of forecasting horizons and destinations being concerned. Therefore, tourism practitioners in this region can feel comfortable using TVP models to forecast future trends and growth rates of tourism demand by UK residents in these destinations. Considering the increasingly competitive environment in the tourism market of this region, such as the strong competition between France and Spain in attracting UK visitors as discussed above, the more accurate forecasts of the demand for these destinations can provide a clearer picture of the future trends of competition. Correspondingly, tourism businesses, such as those in transportation and hospitality sectors, can be more confident of adjusting the existing or taking new strategies in order to win the competition. The predicted growth rates of tourism demand for particular destinations can facilitate tourism businesses' decision making in terms of identifying the optimal investment opportunity amongst alternative nations, or deciding the appropriate scale and pace of business expansion in a particular destination if UK visitors are their key source market. In addition, the predicted future change of tourism demand may indicate the positions of the current tourism products in their life cycles. Therefore, tour operators may need to consider modifying the existing packages or designing new products in order to create or sustain their competitive advantages. As far as the public sectors (in both the origin and destination nations) are concerned, the potential socioeconomic effects of the future demand changes need to be studied and the relevant policies should be reviewed and revised accordingly where necessary, in order to ensure the development of tourism follows a healthy path.

\section{CONCLUSIONS}

Within the framework of single-equation econometric approaches to tourism demand forecasting, both the TVP model and ECM have generated relatively accurate forecasts. This paper, for the first time, combines these two approaches to develop the TVP-ECM for tourism demand studies. The forecasting performance of the TVPECM is examined in comparison to several fixed-parameter single-equation econometric methods. The empirical study focuses on the demand for tourism by UK residents at five key destinations in Western Europe. The one- to four-years-ahead ex post forecasting performance of the TVP-ECM and the TVP-LRM is compared with the accuracy of forecasts generated by six commonly used fixed-parameter econometric models: the static model, reduced ADLM, VAR, WB-ECM, JML-ECM and EG-ECM. The naïve no-change and ARMA models also enter the comparison as benchmarks. One- to four-years-ahead forecasts of demand levels and demand growth are examined. The comparison results show that the TVP-ECM and TVP-LRM are ranked top two in general in both demand level and demand growth forecasting. In particular, the TVP-ECM consistently shows its superior performance over other fixed-parameter econometric models and time-series models, regardless forecasting horizons, destinations concerned, and whether demand level or demand growth being forecast. Consistent with previous studies, the TVP-LRM shows outstanding performance in the short-run (one-year-ahead) forecasting of both demand level and growth. By contrast, the static model, taking no dynamics of tourism demand into account, forecasts least accurately. The two univariate model benchmarks are outperformed by all the econometric approaches except the static model. Although the reduced ADLM and JML-ECM perform above average in demand level forecasting 
(so do the EG-ECM and the reduced ADLM in demand growth forecasting) as far as the aggregated forecasts over destinations are concerned, none of them performs consistently well in each individual case of destination. These comparison results suggest that the TVP models, especially the TVP-ECM, are superior over the other forecasting models in terms of both forecasting accuracy and consistency. Therefore, they should be applied more broadly in tourism forecasting practice. It is plausible to expect more accurate forecasts to be generated when the TVP-ECM is applied to other tourism regions, and this will contribute to more effective tourism policies and business strategies projected by public and private sectors, respectively.

It should be noted that the forecasting accuracy comparisons in this study are assessed based on the error measures MAPE and MAE, which do not have a statistical basis. In order words, these measures are unable to examine whether the differences between the forecasting errors generated by alternative models are statistically significant. In order to draw more robust conclusions with regard to the superiority of the TVP models over their fixed-parameter counterparts, formal statistical tests of forecasting differences are required. Little attempt has been made in tourism forecasting so far and this suggests a new direction for further studies. Although Witt, Song, and Louvieris (2003) consider statistically significant differences in forecasting performance as measured by directional changes, the examination of statistically significant differences in error magnitude measures should be of considerable interest. In the current study, the total number of forecasts is extremely small ( 8 to 4 points in one- to four-years-ahead forecasting horizons), and statistical tests tend to be biased as small sample sizes are concerned (Harvey, Leybourne, and Newbold 1997), therefore the statistical test is beyond the discussion of this paper, but will be included in future studies of forecasting comparison.

Moreover, to analyze the seasonal patterns of tourism demand in a particular destination and to forecast future changes of seasonable patterns accurately are of great importance to tourism businesses. In order to achieve these, future studies following this one are to extend the TVP models by introducing stochastic seasonal variables into the TVP-LRM and TVP-ECM specifications and examining the forecasting performance of the developed models. Such studies can also facilitate statistical tests for forecasting difference between various models, which will give more robust conclusion with regard to the evaluation of forecasting performance.

\section{REFERENCES}

Chu, F. L. (1998). "Forecasting tourism demand in Asian-Pacific countries." Annals of Tourism Research, 25: 597-615.

Clements, M. P. and D. F. Hendry (1998). Forecasting Economic Time Series. Cambridge: Cambridge University Press.

De Mello, M., A. Pack, and M. T. Sinclair (2002). "A System of Equations Model of UK T ourism Deand in Neighbouring Countries." Applied Economics, 34: 509-21.

Dritsakis, N. (2004). "Cointegration Analysis of German and British Tourism Demand for Greece.” Tourism Management, 25: 111-19. 
du Preez, J. and S. F. Witt (2003). "Univariate versus Multivariate Time Series Forecasting: An Application to International Tourism Demand." International Journal of Forecasting, 19: 435-51.

Durbin, J. and S. J. Koopman (2001). Time Series Analysis by State Space Methods. New York: Oxford University Press.

Engle, R. F. and C. W. J. Granger (1987). "Cointegration and Error Correction: Representation, Estimation and Testing." Econometrica, 55: 251-76.

Frechtling, D. C. (2001). Forecasting Tourism Demand: Methods and Strategies. Oxford: Butterworth-Heinemann.

Harvey, A. C. (1989). Forecasting, Structural Time Series Models and the Kalman Filter. Cambridge: Cambridge University Press.

Harvey, D., S. Leybourne, and P. Newbold (1997). "Testing the Equality of Prediction Mean Squared Errors.” International Journal of Forecasting, 13: 281-91.

Kalman, R. E. (1960). "A New Approach to Linear Filtering and Prediction Problems, Transitions ASME." Journal of Basic Engineering, 82: 35-45.

Kulendran, N. and K. Wilson (2000). "Modelling Business Travel.” Tourism Economics, 6: 47-59.

Li, G., H. Song and S. F. Witt (2004). "Modelling Tourism Demand: A Dynamic Linear AIDS Approach." Journal of Travel Research, 43: 141-50.

_ (2005a). "Recent Developments in Econometric Modeling and Forecasting." Journal of Travel Research, 44: 82-99.

_ (2005b). "Time Varying Parameter and Fixed Parameter Linear AIDS: An Application to Tourism Demand Forecasting." International Journal of Forecasting, forthcoming.

Lim, C. and M. McAleer (2001). "Cointegration Analysis of Quarterly Tourism Demand by Hong Kong and Singapore for Australia." Applied Economics, 33: 1599-619.

(2002). "Time Series Forecasts of International Travel Demand for Australia." Tourism Management, 23: 389-96.

Narayan, P. K. (2004). "Fiji's Tourism Demand: The ARDL Approach to Cointegration." Tourism Economics, 10: 195-206.

Ramajo, J. (2001). "Time-Varying Parameter Error Correction Models: The Demand for Money in Venezuela, 1983.I-1994.IV." Applied Economics, 33: 771-82.

Song, H. and S. F. Witt (2000). Tourism Demand Modelling and Forecasting: Modern Econometric Approaches. Oxford: Pergamon.

Song, H., P. Romilly and X. Liu (2000). "An Empirical Study of Outbound Tourism Demand in the U.K.." Applied Economics, 32: 611-24.

Song, H., S. F. Witt and T. C. Jensen (2003). "Tourism Forecasting: Accuracy of Alternative Econometric Models.” International Journal of Forecasting, 19: 123-41.

Song, H., S. F. Witt and G. Li (2003). "Modelling and Forecasting the Demand for Thai Tourism." Tourism Economics, 9: 363-87.

Thomas, R. L. (1993). Introductory Econometrics, $2^{\text {nd }}$ edition. London: Longman.

Tucci, M. P. (1995). “Time-Varying Parameters: A Critical Introduction.” Structural Change and Economic Dynamics, 6: 237-60.

Wickens, M. R. and T. S. Breusch (1988). "Dynamic Specification, the Long-Run and the Estimation of Transformed Regression Model." Economic Journal, 98 (Conference): $189-205$. 
Witt, C.A. and S.F. Witt (1989). "Measures of Forecasting Accuracy: Turning Point Error v. Size of Error." Tourism Management, 10: 255-60.

Witt, S.F. and C.A. Witt (1991). "Tourism Forecasting: Error Magnitude, Direction of Witt, S.F., H. Song and P. Louvieris (2003). "Statistical Testing in Forecasting Model Selection." Journal of Travel Research, 42: 151-58.

Witt, S. F. and C. A. Witt (1991). "Tourism Forecasting: Error Magnitude, Direction of Change Error and Trend Change Error." Journal of Travel Research, 30: 26-33. 